
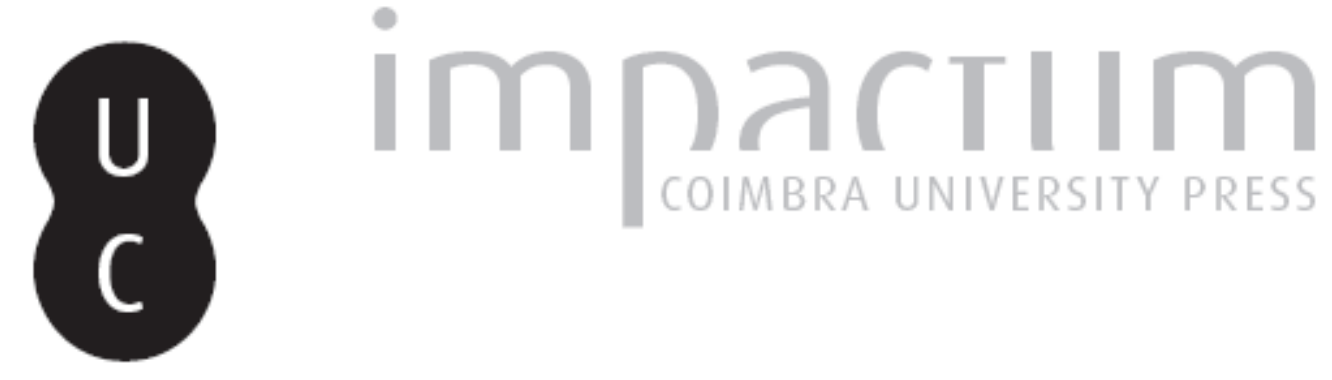

\title{
As inundações em Ururaí e o ensino de Geografia: uma análise da percepção desses eventos por adolescentes da rede pública de ensino
} \author{
Autor(es): $\quad \begin{array}{ll}\text { Almeida, Carolina Vieira Caldeira de Lima de Souza; Leite, Adriana } \\ \text { Filgueira }\end{array}$
}

Publicado por: Imprensa da Universidade de Coimbra

URL

persistente:

URI:http://hdl.handle.net/10316.2/44197

DOI:

DOI:https://doi.org/10.14195/1647-7723_25-2_9

Accessed : $\quad$ 26-Apr-2023 11:08:39

A navegação consulta e descarregamento dos títulos inseridos nas Bibliotecas Digitais UC Digitalis, UC Pombalina e UC Impactum, pressupõem a aceitação plena e sem reservas dos Termos e Condições de Uso destas Bibliotecas Digitais, disponíveis em https://digitalis.uc.pt/pt-pt/termos.

Conforme exposto nos referidos Termos e Condições de Uso, o descarregamento de títulos de acesso restrito requer uma licença válida de autorização devendo o utilizador aceder ao(s) documento(s) a partir de um endereço de IP da instituição detentora da supramencionada licença.

Ao utilizador é apenas permitido o descarregamento para uso pessoal, pelo que o emprego do(s) título(s) descarregado(s) para outro fim, designadamente comercial, carece de autorização do respetivo autor ou editor da obra.

Na medida em que todas as obras da UC Digitalis se encontram protegidas pelo Código do Direito de Autor e Direitos Conexos e demais legislação aplicável, toda a cópia, parcial ou total, deste documento, nos casos em que é legalmente admitida, deverá conter ou fazer-se acompanhar por este aviso.

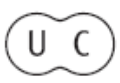




\title{
AS INUNDAÇ̃̃ES EM URURAÍ E O ENSINO DE GEOGRAFIA: UMA ANÁLISE DA PERCEPÇ̃̃O DESSES EVENTOS POR ADOLESCENTES DA REDE PÚBLICA DE ENSINO*
}

\section{FLOODS IN URURAÍ AND GEOGRAPHY EDUCATION: AN ANALYSIS OF THE PERCEPTION OF THESE EVENTS BY ADOLESCENTS IN PUBLIC SCHOOLS}

\author{
Carolina Vieira Caldeira de Lima de Souza Almeida \\ Universidade Federal Fluminense (Brasil) \\ ORCID 0000-0003-1585-0975 v.c.l.s.a.carolina@gmail.com \\ Adriana Filgueira Leite \\ Departamento de Geografia - Universidade Federal Fluminense (Brasil) \\ ORCID 0000-0003-3154-7909 adrianafilgueiraleite@id.uff.br
}

\begin{abstract}
RESUMO
O presente estudo foi desenvolvido com o objetivo de propor práticas de ensino que trouxessem maior dinamismo à construção do conhecimento em sala de aula, a partir das percepções que os alunos possuem sobre o fenômeno que permeia a realidade desses, as inundações. Para tanto, tomou-se como amostra os alunos do bairro Ururaí em Campos dos Goytacazes (RJ), em específico os alunos da rede pública de ensino no $9^{\circ}$ ano do Ensino Fundamental em 2015 e do $1^{\circ}$ ano do Ensino Médio em 2016. As atividades realizadas com os alunos perpassaram entrevistas, aplicação de questionários, análise de mapas temáticos do bairro, aulas de campo, atividades lúdicas e apresentação de seminário. Por fim, as diversas práticas realizadas nesse trabalho mostraram-se como ferramentas eficazes no desenvolvimento da percepção crítica do alunado, tanto a respeito do ambiente vivido, quanto no que se refere aos desastres relacionados à água.
\end{abstract}

Palavras-chave: Alunos, risco, prática de ensino em geografia.

\section{ABSTRACT}

The present study was developed with the purpose of proposing teaching practices that would bring greater impetus to building knowledge in the classroom, based on the students' perceptions about the phenomenon that permeates the reality of these, the floods. Therefore, students from the Ururai neighborhood in the municipality of Campos dos Goytacazes (RJ) were sampled. More specifically the students were from public schools system in the $9^{\text {th }}$ year of primary education in 2015 and the 1st year of secondary education in 2016 . The activities carried out with the students included interviews, the application of questionnaires, analysis of thematic maps of the neighborhood, field lessons, play activities and seminar presentation. These activities proved to be effective tools for developing the critical perception of students, both regarding the environment around them and in relation to disasters related to water.

Keywords: Students, risk, geography teaching practices.

\footnotetext{
* O texto deste artigo corresponde a uma comunicação apresentada no IV Congresso Internacional de Riscos, tendo sido submetido em 01-07-2017, sujeito a revisão por pares a 22-09-2017 e aceite para publicação em 08-01-2018. Este artigo é parte integrante da Revista Territorium, $n .{ }^{\circ} 25$ (II), 2018, ${ }^{\circ}$ RIscos, ISSN: 0872-8941.
} 


\section{Introdução}

A geografia como uma ciência dinâmica, complexa, que dialoga com as demais áreas do conhecimento propicia uma leitura e compreensão crítica do mundo e pode ser utilizada como uma ferramenta na redução de riscos e desastres. Neste artigo os autores tiveram como objetivo principal desenvolver um diálogo entre as diferentes ciências que abordam temas como: hazards, risco e perigo, a fim de enriquecer mutuamente os conceitos desenvolvidos nas diferentes áreas do conhecimento.

De acordo com Marandola e Hogan, esta tem se dedicado desde a década de 1920 no estudo dos natural hazards, direcionando a questão para a relação homem-meio/ sociedade-natureza, incidindo a ação antrópica sobre o ambiente. Denota-se que para os autores "[.. ] um hazard não é natural em si, mas trata-se de um evento que ocorre na interface sociedade-natureza" (E. Jr., Marandola; D. J. Hogan, 2004, p.98). Neste viés entre sociedade e natureza e sua relação, o ensino de geografia pode contribuir na redução de riscos e desastres, favorecendo uma política de prevenção e mitigação de riscos.

A autora Souza aponta também este viés e sua contribuição ao citar a Geografia como um campo onde a “convergência e o entrelaçamento das ciências naturais e sociais apresentam potencial de discussão [...] à luz da interação Sociedade/Natureza e Riscos". (C.J.O. Souza, 2013 p.133). Ainda segundo a autora, há uma dialética entre essa interação Sociedade/Natureza uma vez que a intervenção da sociedade sobre os "elementos da natureza ocasiona alterações que deflagram efeitos $e$ impactos negativos, que por sua vez se "protege" com novas intervenções” (C.J.O. Souza, 2013 p.132).

Para a UNESCO, a educação formal em sua forma mais abrangente, sem exemplificar disciplinas, pode contribuir diretamente para a redução do risco de desastres, pois constitui-se "uma construção da compreensão dos alunos sobre as causas, natureza $e$ efeitos dos riscos e que ao mesmo tempo promove uma série de competências e habilidades que lhes permitam contribuir de forma proativa para a prevenção $e$ mitigação dos desastres" (UNESCO; UNICEF; F. Kagawa; D. Selby, 2012, p.30). Neste contexto de uma educação proativa para a prevenção e mitigação dos desastres se insere o presente trabalho. Com a proposta de trazer uma contribuição para o ensino da geografia e para a prevenção de desastres relativo a água, em específico as inundações, o objetivo principal do trabalho foi de propor metodologias viáveis de se aplicar em sala de aula, de forma a permitir maior dinamismo na construção do conhecimento geográfico e na prevenção dos eventos de inundação. Pata tanto, a presente pesquisa fez uso da percepção dos alunos e juntamente com esses a análise do fenômeno mencionado.
A mitigação no sentido de aliviar os impactos gerados pelo fenômeno e a prevensão no sentido de evitar que este ocorra como sinaliza Campos, para "el sentido común, «prevenir» significa actuar con anticipación para evitar que algo ocurra. En lo que se refiere a los desastres, el significado del término es básicamente el mismo, pero se crean ciertas confusiones a la hora de precisar qué es lo que se quiere evitar" (A. Campos, 1999, p.45).

O público-alvo da investigação que foi iniciada em 2015 contou com 120 estudantes do último ano do Ensino Fundamental da rede pública de Ururaí, na faixa entre 14 e 19 anos. Já em 2016 o grupo contou com aproximadamente 100 estudantes do primeiro ano do Ensino Médio. 0 grupo foi selecionado devido a dois fatores primordiais a saber, primeiro a localidade Ururaí situada no município de Campos dos Goytacazes enfrenta problemas relacionado às inundações o que coloca esses estudantes em condições de vivência com este fenômeno. Outro fator faz referência ao currículo escolar proposto pela Secretaria de Educação do Estado do Rio de Janeiro, pois neste há maior possibilidade de desenvolver o tema inundações com os estudantes do primeiro ano do Ensino Médio.

\section{Caracterização da Área de Estudo e as inundações}

Primeiramente, cabe aqui destacar que a inundação se constitui um conceito diferente de enchente, apesar de ambas estarem estreitamente relacionados. Do ponto de vista hidrológico, para Barros o conceito de cheia ou enchente ocorre na bacia hidrográfica toda a vez em que a precipitação fornece um aumento do nível d'agua sem que ocorra transbordamento, devido ao escoamento superficial. Enquanto que a inundação se trata do extravasamento da água devido ao aumento de vazão, ou seja, o rio sai do seu leito (calha) menor e passa a ocupar o seu leito maior (M. T. L. Barros, 2005, p. 228).

Outro autor que faz essa diferenciação conceitual, Rocha relaciona o termo cheia e inundação. "O conceito de cheia está associado à ocorrência de um valor muito elevado de caudal num curso de água, resultante da ocorrência de precipitação intensa. Quando a cheia provoca o transbordamento do leito normal, dá-se a inundação dos terrenos marginais" (J. S. Rocha, 1995, p.11). Acrescenta-se ao conceito cheia a proposta de Rebelo de que essas "são fenômenos hidrológicos resultantes de precipitações elevadas e de certas características das bacias hidrográficas" (F. Rebelo, 2010, p.86).

De acordo com Leopold, a inundação ocorre quando o fluxo de água avança além dos bancos naturais ou artificiais de um determinado canal "A flood may be defined as the occurrence of a flow of such magnitude that it overtops the natural or artificial banks in a 
reach of river channel" (L. B. Leopold, 1994, p. 113). Assim, este fenômeno se manifesta quando a vazão se torna maior que a capacidade do canal atingindo o leito superior do rio.

Para Ramos, às inundações trata-se de um fenômeno hidrológicos relacionados à dinâmica fluvial natural, os quais ocorrem quando os rios transbordam em direção às superfícies que os margeiam alcançando os terrenos ribeirinhos (C. Ramos, 2005, p.71).

Ainda acerca do fenômeno, para Knight as inundações podem ser diferenciadas pelo tipo e por sua configuração. A primeira para o autor pode ser dividida em "flash floods" quando ocorre de forma rápida e instantânea e a "long period floods" onde a inundação para ocorrer demanda mais tempo, uma inundação gradual. Quanto a configuração, ele coloca que pode ser classificada em inundação fluvial, urbana ou costeira. 0 autor define que a inundação fluvial é quando o rio excede o seu fluxo interno em direção a planície de inundação devido ao fluxo excessivo. A urbana normalmente ocorre quando a capacidade de drenagem se torna insuficiente por intermédio dos mananciais, sistemas canalizados de água e esgoto e por fim, a inundação costeira que ocorre devido a morfologia característica desses ambientes com sobreposição de aterros costeiros, a destruição de quebra-mares dentre outros.

"It is also important to distinguish between different types of flood (flash floods \& long period floods), as well the predominant setting (fluvial, urban and coastal flooding). Fluvial flooding is commonly identified with a river exceeding its bankfull discharge (i.e. inbank flow) and then flowing on to its surrounding floodplains (overbank flow). Urban flooding is often identified with insufficient drainage capacity via urban watercourses and piped systems, with interaction from on underground sewerage system and also perhaps from fluvial inputs. Coastal flooding may be associated with overtopping of coastal embankments, high tide levels in estuaries backing up water levels elsewhere and destruction of breakwaters under abnormal wave conditions"

(D. W. Knight, 2006, p.4).

Sobre as inundações urbanas, Barros acrescenta a impermeabilização do solo como um fator chave que gera uma diminuição no processo de infiltração e o consequente aumento no escoamento superficial.

"As inundações urbanas são provocadas fundamentalmente pelo excesso de escoamento superficial, chamado de chuva excedente ou de chuva efetiva, gerado pelo aumento dos índices de impermeabilização do solo e por conseguinte da diminuição dos processos de infiltração e de retenção de agua. Quando o volume de escoamento superficial gerado ultrapassa a capacidade de escoamento dos cursos d'agua que drenam as cidades, ocorrem as inundações"

(M. T. L. Barros, 2005, p.228).

Por fim, salientamos aqui a abordagem de inundação proposta por Gregory e Walling, onde os autores elencam alguns fatores que levam a inundação como chuvas de alta intensidade, o degelo, tempestades após um período longo de chuvas, falhas de barragens, drenagem de lagos subglaciais, erupções vulcânicas em área de geleiras e a atividade humana.

"River floods can be the results of high intensity rainfall and therefore flooding is an annual occurrence in some climatic zones. High discharges leading to flooding can also be occasioned by snow melt, by storms following $a$ period of prolonged rainfall and by specific causes including dam failure, drainage of subglacial lakes, volcanic eruptions beneath glaciers causing glacier busts. The frequency of river floods may have been influenced by human activity" (K. J. Gregory; D. E. Walling, 1973, p.4).

O núcleo urbano chamado de Ururaí localiza-se no município de Campos dos Goytacazes, Estado do Rio de Janeiro, Brasil (fig. 1) e as inundações constituem um fenômeno que permeia a realidade dos moradores, onde esse estudo foi desenvolvido. A localidade se encontra às margens do rio do mesmo nome, Ururaí e de um canal denominado Cacumanga. Segundo relatório produzido pelo NESA (Núcleo de Estudos Sócio Ambientais - UFF, Campos dos Goytacazes), a formação do atual núcleo urbano tem suas raízes no meio rural, em particular ao cultivo de cana-de-açúcar e à Usina Cupim. Em 2010, com um total de 8.787 moradores, cuja renda per capita das pessoas era de $\mathrm{R} \$ 344,60$, no período em que o salário mínimo era no valor de R\$ 510,00, em $79 \%$ dos domicílios a renda nominal mensal era de até um salário mínimo. Logo o bairro é formado, em sua maioria, por famílias com baixa remuneração pelo trabalho (NESA, 2016, p.7).

Os dados utilizados para averiguação de que se trata de famílias com baixa remuneração pelo trabalho foram retirados do IBGE, Instituto Brasileiro Geografia e Estatística referente ao Censo realizado em 2010 e da própria pesquisa que o NESA realizou no período de 2012 até 2016 subsidiado pela FAPERJ - Fundação de Amparo à Pesquisa do Estado do Rio de Janeiro.

Ururaí faz parte da Baixada Campista que é uma grande planície flúvio-marinha marcada pela topografia plana e a presença de uma extensa rede fluvial e de lagoas. 0 rio Ururaí nasce na Serra do Mar com o nome de Rio Imbé, deságua na Lagoa de Cima e a partir desta já com o 


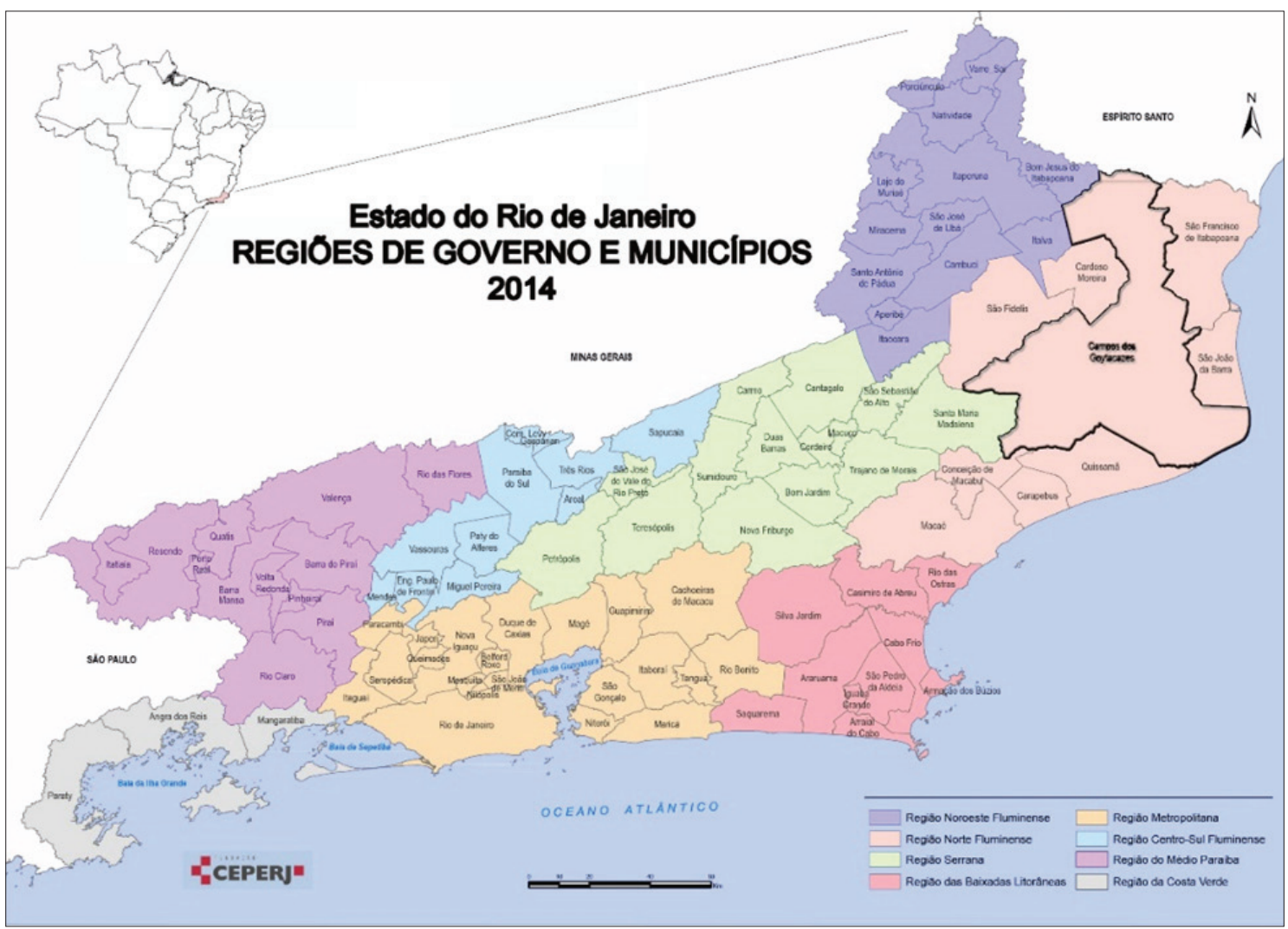

Fig. 1 - Ampliado a localização do Estado do Rio de Janeiro e em destaque o município de Campos dos Goytacazese (Fonte: adaptado por C. Almeida, a partir da Fundação CEPERJ, 2013).

Fig. 1 - Expanded the location of the State of Rio de Janeiro and highlighted the municipality of Campos dos Goytacazes (Source: adapted by C. Almeida, from the CEPERJ Foundation, 2013).

nome de Rio Ururaí, deságua na Lagoa Feia (fig. 2). Além da rede tributária natural, o Rio Ururaí possui também canais artificiais que o interligam ao Rio Paraíba do Sul, que é o maior e mais importante do sudeste brasileiro.

Entre os meses de outubro e janeiro ocorre à estação úmida, na qual as chuvas apresentam maior frequência e intensidade, e dão origem às inundações. Para Leite a região Norte Fluminense a qual Ururaí pertence possui "chuvas concentradas no verão ainda que os totais pluviométricos e o comportamento sazonal sejam influenciados pela posição espacial dos postos analisados" (A. F. Leite, 2013, p.30). Devido aos baixos totais pluviométricos anuais, mesmo durante o período do verão, os transbordamentos são eventos episódicos, contudo quando ocorrem costumam ser desastrosos e causam grandes prejuízos socioeconômicos, o quadro ao lado destaca os principais eventos.

\section{Eventos de inundação desastrosos* ocorridos na Região Hidrográfica IX após o ano de 1935.}

De acordo com Malagodi e Siqueira são frequentes as cheias do rio Ururaí (QuADRo I), e historicamente não é raro que transbordem em direção ao núcleo urbano de
QUADRo I - Adaptado por C. Almeida, a partir do relatório Cartografia socioambientais e mapeamento de áreas de risco de inundações no Norte Fluminense: subsídios a elaboração de sisytemas de alerta desenvolvido pelo do NESA, prestado à Fundação FAPERJ, 2016).

TABLE I - Adapted by C. Almeida, based on the report, Social and environmental cartography and mapping of flood risk areas in the North of the state of Rio de Janeiro: subsidies for establishing warning systems developed by the NESA, provided to the FAPER J Foundation, 2016).

\begin{tabular}{|l|l|}
\hline \multicolumn{1}{|c|}{ ANO } & \multicolumn{1}{|c|}{ MÊS } \\
\hline 1943 & Janeiro \\
\hline 1966 & Janeiro \\
\hline 1979 & Janeiro e fevereiro \\
\hline 1985 & Janeiro e fevereiro \\
\hline 1997 & Janeiro \\
\hline 2007 & Janeiro \\
\hline 2008 & Dezembro \\
\hline * Os anos citados foram referenciados como desastrosos \\
mediante o conceito de desastre de DKKV, 2002; EEA, 2005 \\
apud MARRE, 2013 --- SERJE, 2002 apud MARRE, 2013 --.- \\
- Estratégia Internacional para a Redução de Desastres, das \\
Nações Unidas = Serviço de Notícias IRIN, 2005 apud MARRE, \\
2013(Nesa, 2016) \\
\hline
\end{tabular}




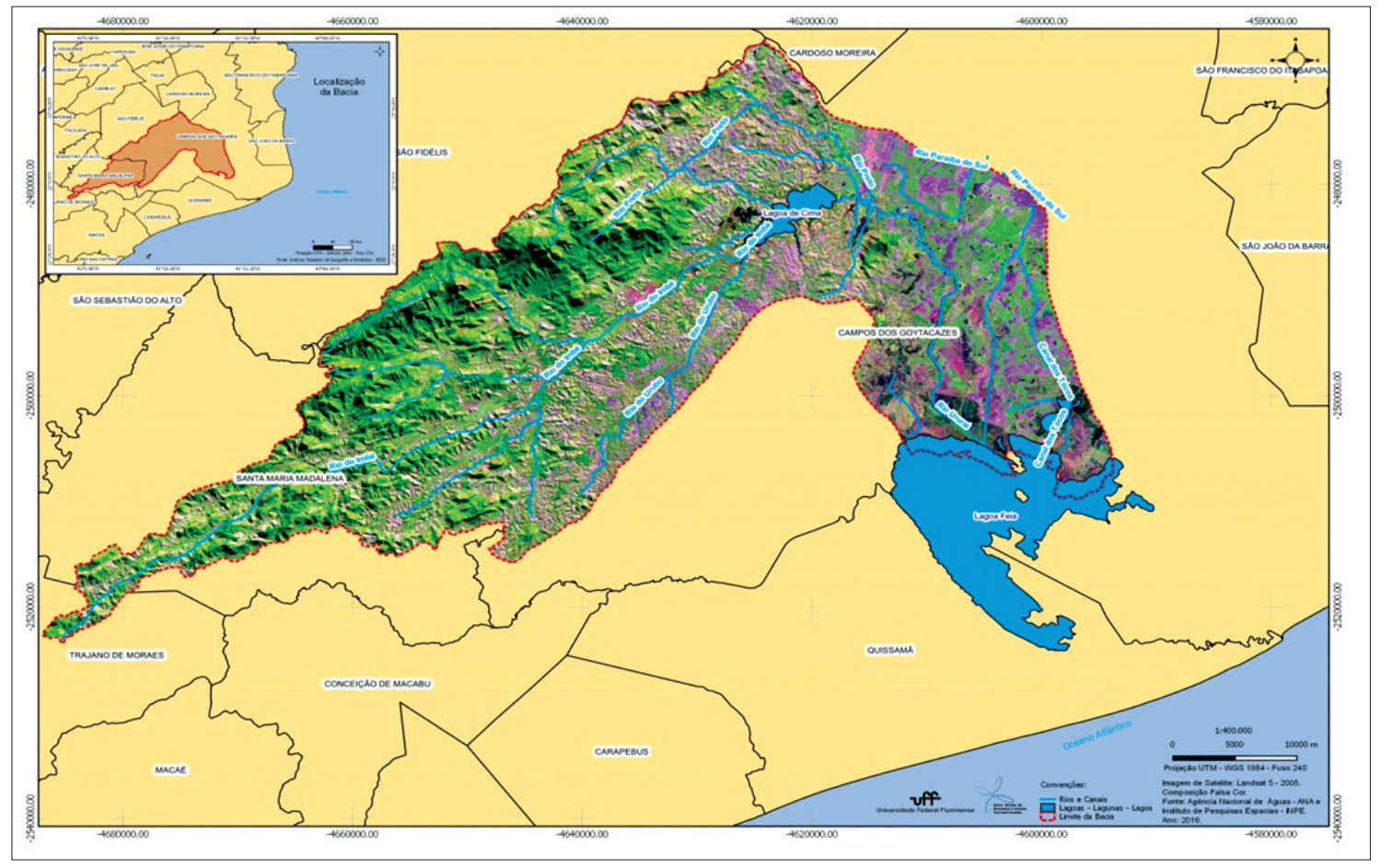

Fig. 2 - Mapa do Sistema hidrografico Imbé - Lagoa de Cima - Rio Ururaí e Lagoa Feia. A parte verde e rugosa pertence a Serra do Mar onde o rio nasce com outro nome. Ao desaguar na Lagoa de Cima (a menor lagoa presente no mapa) passa a se chamar de Ururai.Por fim o rio em questão deságua na Lagoa Feia (a maior lagoa presente no mapa) (Fonte: A. Lemos, 2016).

Fig. 2 - Map of the Imbé - Lagoa de Cima - Ururaí River and Lagoa Feia Hydrographic System. The green, rough part is the Serra do Mar where the river rises, with another name. When it flows into Lagoa de Cima (the smaller lake on the map) it is called Ururai. Finally, it flows into Lagoa Feia, (the larger lake on the map) (Source: A. Lemos, 2016).

Ururaí (M. A. S. Malagodi; A M. M. Siqueira, 2012, p.5). Para os autores em 2008 (fotos 1 e 2) as "características do fenômeno ocorrido nos levaram a considera-lo como um desastre", onde diferentes atores passaram a intervir naquele espaço como a Defesa Civil e o Ministério Público (M. A. S. Malagodi; A M. M. Siqueira, 2012, p.10).

Cabe aqui realizar um esclarecimento com relação alguns conceitos citados no trabalho, como o de risco. Para Rebelo, "o risco corresponde ao sistema complexo de processos cuja modificação do funcionamento é susceptível de acarretar prejuízos directos ou indirectos (perdas de recursos) numa dada população" (F. Rebelo, 2010, p.85). Ainda para o autor "o risco pode ser maior ou menor em função da importância de um determinado acontecimento e da presença do Homem" (F. Rebelo, 2010, p.32). Lourenço exemplifica que o risco pode ser entendido "como algo de potencial, que pode vir a se manifestar ou não e, nessas circunstâncias, parece-nos fazer todo o sentido situá-lo a montante do perigo" (L. Lourenço, 2015, p.9). O autor vai além nesta definição acrescentando que este só é objeto de estudo porque acarreta consequências, sempre que se manifesta com severidade (L. Lourenço, 2015, p.13).
O risco para Thywissen envolve probalidade de ocorrência, isto é, quando pode ocorrer um período de retorno de um evento para outro, a frequência ou a probalilidade do mesmo reincidir.
"Risk always involves the notion of probability of occurrence. So information on "when" or on "how often" indicates we are talking about risk. That could be captured in a continuous damage- frequency relationship or just the definition of the return period for a particular event scenario. While vulnerability informs about the consequences of possible adverse events, risk also provides information on how often or with what probability those scenarios have to be expected" (Thywissen, 2006, p.38).

No caso específico do bairro que foi objeto desse estudo, verifica-se que a topografia local, associada à falta de manutenção dos canais que se encontram assoreados e com comportas defeituosas, são fatores que têm historicamente intensificado os transbordamentos. Outro fator histórico foi a ocupação da área que fora drenada como aponta Siqueira e Malagodi, quando a prioridade de ocupação das áreas mais altas ficou destinada ao cultivo da cana-de-açúcar: 


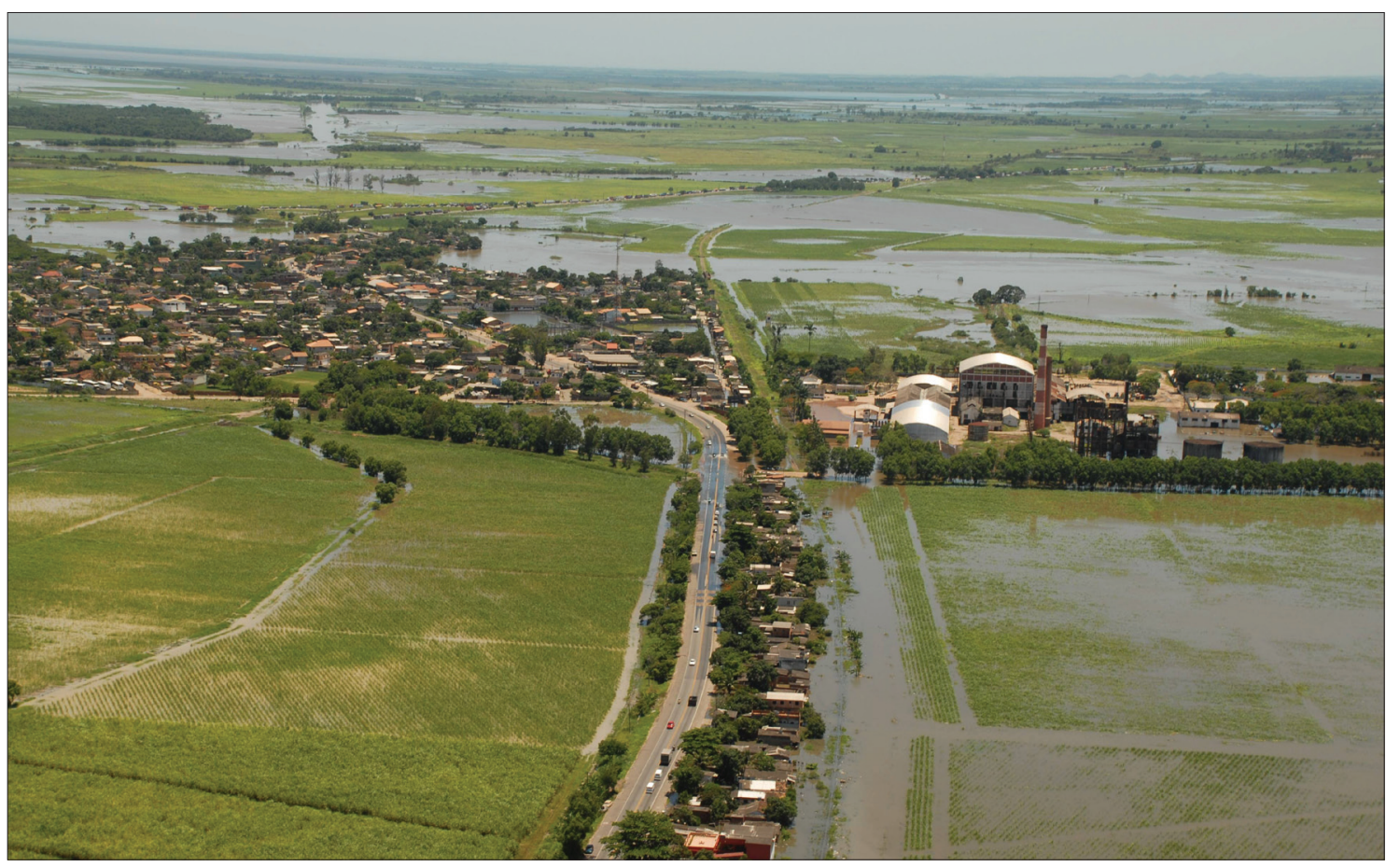

Fot. 1 - Fotografia aérea de Ururaí durante a inundação de 2008 em Campos dos Goytacazes (RJ), Brasil. Nesta é possível notar a extensão da inundação em parte da baixada campista (Fonte: M. B. Lessa, Dezembro de 2008).

Photo 1 - Aerial Photograph of Ururai during the flood of 2008 in Campos dos Goytacazes (RJ), Brazil. The extent of flooding of the low-lying part of the area can be seen (Source: M. B. Lessa, December 2008).

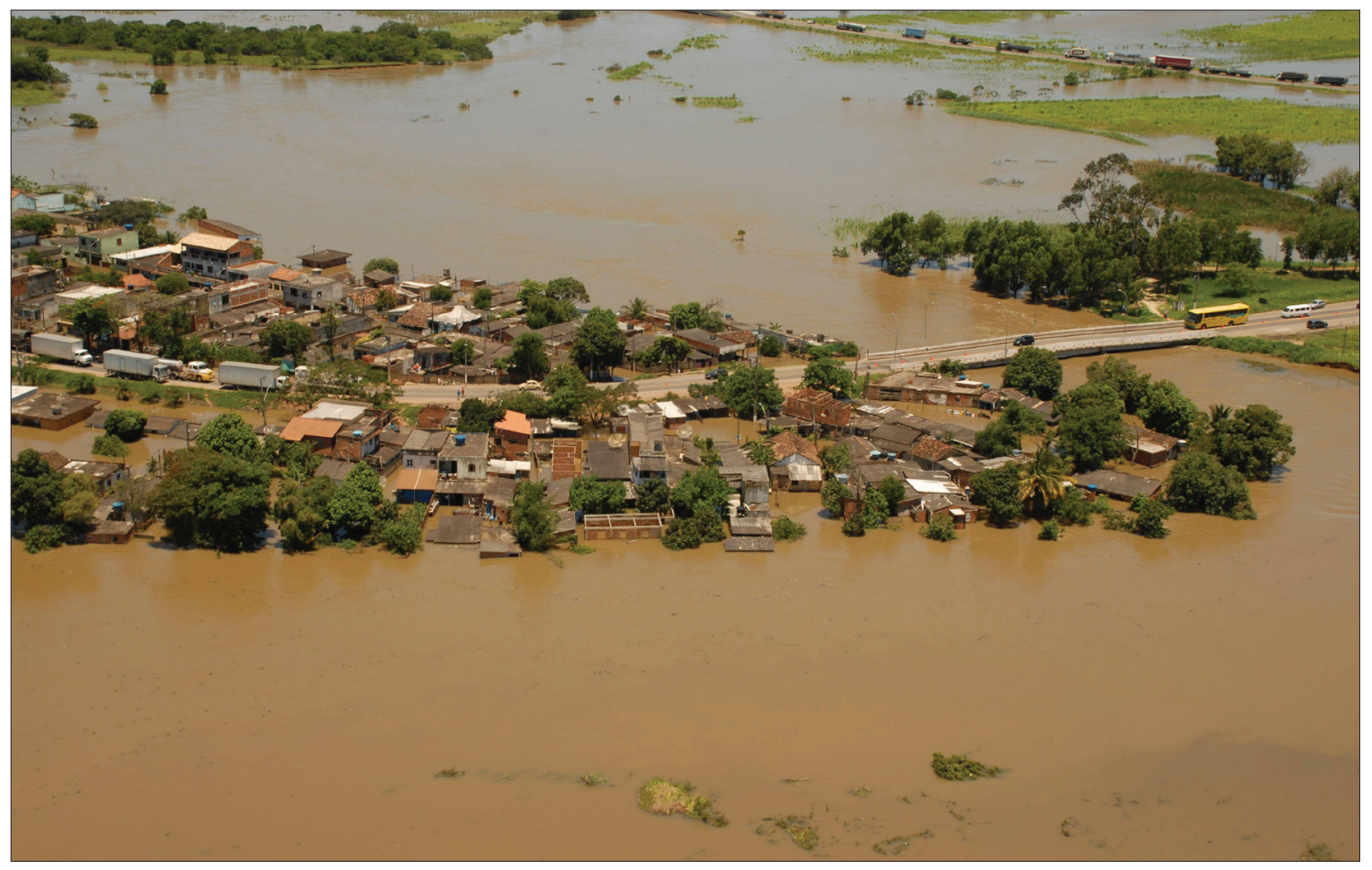

Fot. 2 - Inundação em Ururaí em Campos dos Goytacazes (RJ), Brasil em 2008. Na imagem é possível observar a ponte e o transbordamento do rio (Fonte: M. B. Lessa, Dezembro de 2008).

Photo 2 - Flood in Ururaí in Campos dos Goytacazes (RJ), Brazil in 2008. The bridge and the flooded river can be seen (Source: M. B. Lessa, December 2008). 
"A priorização do uso das terras melhor drenadas para o plantio de cana-de-açúcar, os baixos salários que impediram os trabalhadores de adquirir terrenos em áreas mais altas, assim como a inexistência de planejamento e políticas públicas por muitas décadas para aquele núcleo urbano ocasionou a crescente ocupação de áreas úmidas aterradas e de áreas às margens do rio Ururaí e do canal Cacomanga, seu afluente" (A. M. M. Siqueira; M. A. S. Malagodi, 2013, p. 42).

No caso do último evento desastroso, ocorrido em 2008, houve um fator agravante que foi a presença de diques irregulares (fot. 3) construídos no interior da Lagoa Feia pelos produtores rurais que represaram a água proveniente dos segmentos da bacia posicionados à montante, e deixaram o bairro Ururaí praticamente submerso. Somam-se também a esses fatores, o assoreamento dos mananciais naturais, a ausência da mata ciliar, e o crescimento populacional não acompanhado pela expansão da infraestrutura de água e esgoto.

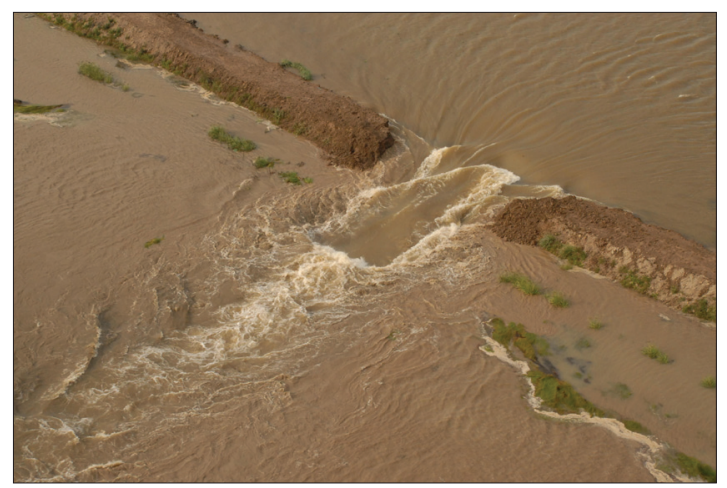

Fot. 3 - Implosão do dique irregular na Lagoa Feia em Campos dos Goytacazes (RJ), Brasil em 2008

(Fonte: M. B. Lessa, Dezembro de 2008).

Photo 3 - Implosion of the irregular dam on the Lagoa Feia in Campos dos Goytacazes (RJ), Brazil in 2008 (Fonte: M. B. Lessa, Dezembro de 2008).

\section{Metodologias no Processo de Ensino/Aprendizagem e a Prática de Ensino de Geografia}

Ao ler e estudar sobre a prática do ensino de Geografia nos defrontamos com uma necessidade de mudança entre uma Geografia que em sua prática se basea em descrição e memorização com uma crítica e de análise dos fenômenos. A título de exemplo, Catrogiovanni analisa essa mudança de paradigmas e coloca que a "Geografia deve se pautar, portanto, pela compreensão dos processos e não na enfadonha forma classificatória", pois esta não busca a compreensão dos processos. Para o autor compreender os processos "é tomar por base a análise objetiva, apreender o conjunto das conexões internas, com suas tensões, seus conflitos; sua gênese, o seu desenvolvimento e as suas tendências" (A. C. Castrogiovanni, 2007, p.19). Essa concepção socioconstrutivista permite que a geografia seja vista como "um conjunto de conhecimentos produzidos/ refletidos na interação sujeito-objeto, como resultado de processos de construção objetiva/subjetiva nas trocas cotidianas com as condições da vida, como um processo de síntese, um resultado da interação" (A. C. Castrogiovanni, 2007, p.18).

Neste viés de uma geografia "resultado de processos de construção objetiva/subjetiva nas trocas cotidianas" a presente pesquisa se fundamentou, voltando-se para um aprendizado significativo, que não se esgota em atividades interessantes e lúdicas buscando também uma participação e interação entre aluno, professor, realidade e habilidades, bem como Goulart indica:

\footnotetext{
"As atividades precisam ser interessantes $e$ lúdicas, mas sua finalidade não pode se esgotar aí. As possibilidades de um trabalho significativo estão ligadas a questões de envolvimento e mobilização dos alunos, mas a isso precisa estar associado o trabalho intencional que inclua a apreensão de conteúdos e habilidades que favoreçam as conexões" (l. B. Goulart, 2014, p.23).
}

Libâneo, outro autor que tem se aprofundado em analisar o processo de ensino e aprendizagem retrata que a "unidade entre ensino e aprendizagem fica comprometida quando o ensino se caracteriza pela memorização, quando o professor concentra na sua pessoa a exposição da matéria, quando não suscita o envolvimento ativo dos alunos" (J. C. Libâneo, 2013, p.98). E este envolvimento é essencial na aprendizagem. A aprendizagem aqui compreende-se como uma "assimilação ativa de conhecimentos e de operações mentais, para compreendê-los e aplicá-los consciente e autonomamente", é a relação cognitiva entre aluno e matéria de estudo, assim o ensino não existe por si mesmo, mas na relação com a aprendizagem, sendo esta a atividade de assimilação de conhecimentos e habilidades do aluno (J.C. Libâneo, 2013, p.99).

Outro autor que relaciona a aprendizagem com as experiências vividas e a compreensão da realidade é Luckesi.

“A aprendizagem ativa é aquela construída pelo educando a partir da assimilação ativa dos conteúdos socioculturais. Isso significa que o educando assimila esses conteúdos, tornando-os seus, por meio da atividade de internalização de experiências vividas. 0 educando se desenvolve à medida que torna propriamente suas as experiências vividas. [...] O conhecimento que se adquire deverá possibilitar a iluminação da realidade, deverá possibilitar ao educando penetrar nos mistérios 
e nas conexões da realidade, desvendando-os. Assim, no conhecimento adqui-rido, é preciso que o educando obtenha um instrumento de compreensão da realidade" (C. C. Luckesi, 2008, p.132).

A compreensão da realidade e dos processos dos fenômenos torna-se fundamental não só no campo da geografia escolar, mas é importante esta compreensão para a prevenção e mitigação dos desastres. Souza afirma que tanto a educação quanto a geografia escolar não podem ficar alheias às questões inerentes ao dia a dia das pessoas e dos alunos, para ela "perceber e entender o perigo, os fenômenos, a área de risco e principalmente os aspectos que fazem a área existir, são fundamentais para que o sujeito aluno possa ter instrumental teórico e conceitual que the possibilite agir sempre que possivel" (C. J. O. Souza, 2013, p.137).

Todo esse tipo de conhecimento a ser construído é desenvolvido por metodologias que possibilitam um processo de aprendizado significativo. Este tipo de aprendizado conceituado por Ausubel dentro da psicologia, ocorre quando uma nova informação se relaciona especificamente a estrutura de conhecimento do indivíduo, interagindo desta forma com a estrutura cognitiva do aluno. Para ele a aprendizagem significativa é muito importante no processo educacional, pois quando esta ocorre permite adquirir e armazenar grande quantidade de idéias e informações:

“Em cambio, el aprendizaje y el olvido de carácter significativo dependen, em primer lugar, de relacionar material nuevo y potencialmente significativo com ideas pertinentes de la estrutura cognitiva del estudiante $y$, em segundo lugar ( $y$ em ausência de um sobreaprendizaje), de la posterior perdida espontânea y gradual de la dissociabilidade de los nuevos" (D.P. Ausubel, 2002, p.30).

Essa concepção da construção do conhecimento, dos conteúdos conceituais pelo sujeito aprendiz Baseandose nos princípios metodológicos do socioconstrutivismo compreende-se que dentro do processo de ensino e aprendizagem a prática deste deve reportar o encontro e o confronto entre a geografia ensinada na academia e a geografia cotidiana, a fim de que haja um encontro entre o espaço vivido pelos alunos e o espaço concebido pela ciência (L. Cavalcanti, 2010 b, p.49). Outra autora a abarcar a concepção de espaço conhecido e vivido pelos alunos no ensino da geografia é Afonso. Ao abordar temas relacionados à dinâmica da natureza ela chama a atenção na busca de conexões entre os educandos com os elementos próximos a realidade desses, de forma que possibilite um confronto entre teoria e realidade. Esta autora ainda acrescenta que apartir do lugar concebido como vivência, identidade e carregado de representações cria novas possibilidades para a concepção curricular.
Nas aulas sobre os temas relacionados à dinâmica da Natureza pode-se buscar conexões com elementos próximos à realidade dos educandos a fim de que eles confrontem teoria e realidade, num processo de produção e aplicação de conhecimento. O levantamento e estudo de problemas socioambientais locais favorecem a produção de conhecimentos articulados, singulares e originais. Ao partir do lugar (espaço conhecido e vivido pelos alunos e professores) como espaço privilegiado para a educação geográfica, surgem novas possibilidades para a concepção de currículo escolar, com base na articulação de experiências locais e conteúdos escolares (A. E. Afonso, 2015 a, p.86).

O estudo ora proposto veio ao encontro desta perspectiva, visto que os conteúdos e o currículo previstos estavam em consonância com a proposta de trabalho de se desenvolver com o tema inundação, que possibilita aos alunos uma melhor compreensão da espacialidade atual, adaptando-se quando necessário às novas necessidades à realidade escolar.

Ainda sobre a abordagem socioconstrutivista, para Cabaní é necessário que a nova informação a ser ensinada aos estudantes se ajuste aos conhecimentos prévios desses, pois do contrário, só ocorrerá memorização de alguns fragmentos do conteúdo de forma isolada (M. Cabaní, 2004, p.195). Assim, para se construir uma base sólida e promover uma aprendizagem significativa é necessário que seja atado tanto o conhecimento exterior, quanto interior do aluno. Nesse sentido, é necessário ver e rever a prática do ensino de geografia, as diferentes metodologias que podem ser utilizadas e até mesmo os vínculos afetivos que são criados, tendo em mente que não há um jeito único de ensinar tal como aponta Zabala, e há a necessidade de se "introduzir, em cada momento, as ações que se adaptem às novas necessidades formativas que surgem constantemente" (A. Zabala, 1998, p.51).

\section{Procedimentos Metodológicos Adotados}

0 estudo realizado utilizou a metodologia de investigação-ação, recorrendo a uma metodologia mista de ordem quantitativa e qualitativa na coleta de dados.

A investigação-Acção pode ser descrita como uma família de metodologias de investigação que incluem acção (ou mudança) e investigação (ou compreensão) ao mesmo tempo, utilizando um processo cíclico ou em espiral, que alterna entre acção e reflexão crítica. "[...] 0 essencial na I-A é a exploração reflexiva que o professor faz da sua prática, contribuindo dessa forma não só para a resolução de problemas como também (e principalmente!) para a planificação e introdução de alterações dessa e nessa mesma prática" (C. P. Coutinho et al., 2009, p.360). 
Foi escolhido a metodologia citada, pois esta contribuiria para a melhoria da prática educativa, visto que a pesquisa demandava o envolvimento, colaboração e diálogo das partes envolvidas na investigação, além da reflexão crítica em todo o processo.

A coleta dos dados ocorreu por meio de questionários individuais e por entrevistas coletivas. Os dados foram tabulados no programa Excel e depois importados para o programa SPSS onde foram analisados e interpretados. Já os dados referentes às observações feitas no trabalho de campo exploratório e nas atividades práticas, foram registrados em um diário de campo, neste anotou-se expressões, comportamentos e falas.

No que se refere ao embasamento teórico, o presente estudo abrangeu os temas ensino, ensino de geografia, prática de ensino, desenvolvimento psicológico e o ensino, inundações, risco, vulnerabilidade e percepção ambiental.

Conforme já mencionado, o estudo foi iniciado em 2015 e a princípio contou com 120 alunos. Em 2016 pouco mais de 100 alunos participaram das atividades práticas. Essa diminuição é comum quando se trata de um painel amostral, onde há várias unidades amostrais acompanhadas ao longo do tempo. Em questão foi realizado um censo com o grupo em 2015 atingindo a participação de $100 \%$ do universo, todavia no ano de 2016 o universo selecionado não foi $100 \%$ alcançado, pois como dito durante os dois anos alguns alunos foram retidos no $9^{\circ}$ ano do Ensino Fundamental e outros foram evadidos. Para a seleção da amostra foram realizados estudos exploratórios de observação com o uso de um diário de campo que permaneceu em uso até o final da pesquisa.

Após a seleção do universo que seria desenvolvido a pesquisa, foi aplicado um questionário com perguntas de ordem qualitativa e quantitativa, abertas e fechadas, com respostas discursivas, simples, de múltipla escolha, de escala onde é possível atribuir diferentes valores como uma nota. 0 objetivo deste foi fazer um levantamento da percepção dos alunos sobre o meio ambiente, o ensino, o risco e as inundações. Além disso, a partir da análise das respostas foi possível montar um perfil do alunado e elaborar as atividades práticas.

Durante todo o processo foram realizadas reuniões com os professores das turmas para obter dados referentes aos alunos, ao ensino, a escola, formação, didática aplicada, organização das atividades realizadas, conteúdos trabalhados e avaliação.

A respeito das atividades, essas ocorreram em grupos como propõem Severino e Severino, na medida em que favorecem a interação entre os seus integrantes, potencializam e enriquecem a aprendizagem (A. Severino e E. Severino, 2012, p.93).
0 primeiro recurso utilizado com as turmas foi um vídeo (fot. 6). Neste era possível ver a extensão da inundação do evento de 2008, por meio de uma filmagem aérea, com o objetivo de apurar a memória a respeito do evento citado, introduzir o tema inundações e a explanação da pesquisa propriamente.

A primeira atividade chamada de "Batalha naval", teve como objetivo principal relembrar os estudantes e avaliá-los sobre o uso de coordenadas geográficas e localização em mapas, a fim de realizar com esses a atividade "Descubra a inundação" que demandava da apropriação dessas habilidades para sua execução. $\mathrm{Na}$ segunda atividade denominada "Encontre os erros", foi utilizado um mapa temático local com erros propositais.

Por fim, os alunos participaram de outro jogo, "Descubra a inundação", onde a partir do uso de imagens do Google Maps impresso e com dicas de coordenadas geográficas, os grupos colaram adesivos em locais em que ocorriam as inundações no bairro. A autora Afonso aponta a possibilidade do uso do Google Maps e Google Earth como ferramentas para identificação de situações de risco natural, "As imagens Google Maps ou as ferramentas Google Earth, por exemplo, viabilizam o acesso a bases cartográficas para localização de pontos críticos no que se refere a riscos naturais [...]". Os professores de Geografia podem lançar mão desses recursos para identificar situações de risco nas proximidades das escolas em que atuam (A. E. Afonso, 2015 b, p.194). Nesta atividade o objetivo era de além treinar as habilidades e competências propostas pelo currículo naquele bimestre, eles pudessem identificar os principais pontos de vulnerabilidade. Como vulneralibilidade compreendemos o que Acosta reconhece ser uma característica dos indivíduos e dos grupos sociais diante de determinadas circunstâncias, se referindo a suceptibilidade de sofrer danos e perdas devido aos fatores produzidos pela sociedade que provocam condições instáveis ao meio ambiente. " $L a$ vulnerabilidad es, así, una característica de los individuos o de grupos sociales ante determinadas circunstancias. Se refiere a la susceptibilidad de sufrir daño y pérdidas debido a factores socialmente construidos que provocan condiciones inestables en el medio ambiente" (V. G. Acosta, 2015, p.48). Para Ayala a vulnerabilidade é a propensão de um elemento sofrer diferentes graus de perda ou dano, dependendo de suas condições sociais, econômicas, culturais e políticas devido a qualquer tipo de risco natural. "Hence, vulnerability can be defined as the propensity of an endangered element due to any kind of natural hazard to suffer different degrees of loss or zamount of damage depending on its particular social, economic, cultural, and political weaknesses" (I. A. Ayala, 2002, p.119). Alguns dos pontos escolhidos pelos alunos também foram selecionados posteriormente 
para a aula de campo, visto que são os mais propensos às inundações e são locais de alta vulnerabilidade com a presença de famílias de baixa renda.

A aula de campo foi outro procedimento de ensino utilizado com os alunos, pois como propõe Stefanello (A. Stefanello, 2009, p.49) no campo todos os sentidos ("ver, cheirar, tocar e ouvir") são expostos, algo que permite o estudante capturar diferentes informações. Além disso, as aulas de campo se constituem espaços que permitem a correlação entre a teoria e a prática e rompem em certo nível, as relações sociais e políticas implícitas na escola em razão de propiciar ao aluno a saída desta e de sua organização espacial (M. Fantin e N. Tauscherk, 2005, pp.109-110). A proposta de levar o aluno ao campo toma como ponto de partida o conhecimento prévio, alimentado pela teoria e reforçado com a observação direta da realidade "[...] onde ele fará o aprendizado e passará a entender as contradições e o processo de apropriação da natureza, entendendo melhor sua dinâmica" ( L.M.S. Tomita, 1999, p.14).

Para que a aula de campo ocorresse foram selecionados anteriormente a sua realização, dois pontos de alta vulnerabilidade e risco do bairro. Também houve uma aula pré-campo, na qual foram fornecidas informações gerais sobre o trabalho como vestimenta, roteiro do campo e divisão dos temas que os alunos iriam pesquisar a partir da aula. Em campo, foram analisados um mostrando a bacia a qual o Rio Ururaí pertence, e os outros dois mostraram as inundações de dois eventos de maior relevância. Os alunos também utilizaram máquinas fotográficas, celular e caderno para o registro da aula.

A partir da aula de campo, os alunos foram divididos novamente em grupos para a realização de uma pesquisa e apresentação da mesma. Os grupos que escolheram os temas antes do campo tiveram um tempo curto, mas viável para prepararem a pesquisa e sua apresentação. Os temas retratavam o bairro e o processo de inundação em diferentes interfaces e estavam de acordo com os vários pontos teóricos apresentados pelos professores ao longo no ano letivo. Os pontos teóricos lecionados se encontram nos quatro eixos temáticos apresentados no QUADRO II.

Este procedimento criou a oportunidade de se criar situações para a realização de investigações de campo, com o objetivo de iniciar o aluno no trabalho científico, posicionamento este que é corroborado por Severino e Severino (A. Severino e E. Severino, 2012, p.34). Desta forma, os estudantes tiveram a possibilidade de desenvolver a pesquisa, a coleta e a sistematização dos dados, assim como correlacionar o currículo com o seu cotidiano, de forma a tentar preparar, prevenir e mitigar resolver uma situação problema que são as inundações.
QUADRo II - Identificação dos temas abordados nos bimestres em todas as escolas públicas no Estado do Rio de Janeiro (Fonte: adaptado por C. Almeida, a partir do Currículo Mínimo de Geografia, SEEDUC, 2012, p.14).

TABLE II - Topics addressed in the bimesters in all public schools in the State of Rio de Janeiro (Source: adapted by C. Almeida, based on the Minimal Curriculum of Geography, SEEDUC, 2012, p.14).

\begin{tabular}{|c|c|}
\hline BIMESTRE & EIXO TEMÁTICO \\
\hline $1^{\circ}$ & Representações gráficas e cartográficas \\
\hline $2^{\circ}$ & A dinâmica climática e os biomas \\
\hline $3^{\circ}$ & $\begin{array}{l}\text { Dinâmica ambiental: as transformações do } \\
\text { relevo e as bacias hidrográficas }\end{array}$ \\
\hline $4^{\circ}$ & A questão ambiental \\
\hline
\end{tabular}

Com o objetivo de avaliar o desenvolvimento da pesquisa e coletar alguns dados pertinentes à mesma, foi realizado o jogo "Tabuleiro humano", onde a partir de um dado os alunos percorriam as casas de um tabuleiro ao responderem perguntas alusivas aos temas desenvolvidos no trabalho de campo e no seminário. Ao longo das atividades diferentes tipos de jogos foram desenvolvidos com os alunos. Esse procedimento baseou-se no princípio segundo o qual as atividades lúdicas "envolvem ações estratégicas, emoção e raciocínio lógico" que favorecem a ação educativa (A. Stefanello, 2009, p.112). Tais atividades tiveram como objetivo desenvolver conteúdos, habilidades e competências estabelecidos no currículo da série escolar com a qual se trabalhou, bem como reconhecer ruas, estruturas do bairro e pontos de inundação locais. Por fim, outro questionário com perguntas abertas e fechadas referentes às atividades desenvolvidas foi aplicado aos alunos.

\section{Resultados e Discussão}

Para melhor compreensão esta etapa do trabalho foi dividida de acordo com o QUADRO III.

QUADRo III - Quadro esquemático mostrando como foi realizado a organização dos resultados.

$T_{A B L E}$ III - Schematic diagram showing how the results were organized.

\begin{tabular}{|c|c|c|}
\hline \multicolumn{3}{|c|}{ RESULTADOS E DISCUSSÃo } \\
\hline \multicolumn{3}{|c|}{ Questionário - ano de 2015 } \\
\hline $\begin{array}{c}\text { Caracterização do grupo e } \\
\text { percepção sobre o ensino }\end{array}$ & $\begin{array}{c}\text { Percepção sobre o meio } \\
\text { ambinete, inundações e riscos }\end{array}$ \\
\hline \multicolumn{2}{|c|}{ Atividades desenvolvidas nas aulas - ano 2016} \\
\hline $\begin{array}{c}\text { Recurso diático: } \\
\text { vídeo e jogos }\end{array}$ & $\begin{array}{c}\text { Recurso didático: } \\
\text { aula de campo }\end{array}$ & $\begin{array}{c}\text { Recurso didático: } \\
\text { pesquisa e apresentação }\end{array}$ \\
\hline \multicolumn{2}{|c|}{ Questionário e entrevistas pós-atividades - ano 2016 } \\
\hline
\end{tabular}


Questionários - ano 2015: caracterização do grupo e percepção sobre ensino.

O grupo que participou do presente estudo era constituído por alunos de baixa renda, característica essa pertinente a maior parte dos moradores como já foi anteriormente exposto. A faixa etária entre 14 e 19 anos com residências no bairro ou em áreas próximas há mais de dez anos, não possuíam expectativa de pleitear um curso de ensino superior e 55\% já repetiram o ano escolar.

Dentre os $55 \%$ que afirmaram ter repetido o ano escolar ao menos uma vez, os principais motivos alegados foram: a falta de interesse pelos estudos e a influência de relacionamentos como influenciador na evasão escolar e reprovação.

Por se tratar do ensino para a prevenção de riscos, foi necessário fazer um levantamento dos tipos de atividades que os alunos estão habituados, como é a interação deles em sala de aula, a fim de elaboras estratégias que pudessem de fato seram alcaçadas.

A explicação do professor, filmes, documentários e as atividades de campo foram citados como recursos que poderiam ser usados para melhorar as aulas. Ainda sobre o professor, $56 \%$ afirmaram que quando estes se importam com a vida do aluno, a aprendizagem é facilitada. Associado a esta facilidade $75 \%$ disseram que a amizade com os colegas é um fator fundamental para que esta ocorra.

Sobre os tipo de recursos que podem ser usados em aula, observou-se que os estudantes estão habituados com o uso de mapas e meios audiovisuais nas aulas. Todavia, somente $28 \%$ estavam familiarizados com as atividades de campo, ainda que $32,5 \%$ tenham afirmado já terem participado desse tipo de prática ao menos uma vez ao longo da sua vida escolar. A baixa adesão às atividades de campo está associada principalmente às complicações encontradas para o transporte dos alunos o que dificulta o acesso a esse tipo de atividade.

Questionários - ano 2015: percepção sobre meio ambiente, inundações e risco.

A respeito da percepção dos estudantes sobre meio ambiente, inundações e risco, 98\% dos entrevistados afirmaram que existem rios na cidade, todavia somente 48\% lembraram-se do Rio Ururaí, que faz parte do bairro, logo na memória dos entrevistados este não teve expressiva representação. A maioria, $72 \%$, se lembrou do Rio Paraíba do Sul que é constantemente mencionado nos meios de comunicação (fig. 3). É importante ressaltar que este rio se encontra distante da localidade (a cerca de $10 \mathrm{~km}$ de distância), sendo mais visto pelos entrevistados quando se dirigem ao centro da cidade.
Ainda no que se refere aos recursos hídricos que formam a bacia na qual o Rio Ururaí está inserido, quando o tema são as lagoas, 96\% afirmaram que há lagoas na cidade, porém, a maioria dos alunos lembrou-se apenas de uma das lagoas, a Lagoa de cima (86\%) A justificativa para este resultado é o fato de possuírem o costume de frequentála, principalmente nas férias, devido a sua maior acessibilidade por meio do uso do transporte público. Já a Lagoa Feia, que é onde o Rio Ururaí deságua, somente cerca de $27 \%$ lembraram (fig. 3 ).

A cerca do sistema hídrico direcionado aos canais, os entrevistados possuem familiaridade com o termo "valão", que apesar de ter um sentido pejorativo, é fiel à realidade da maioria dos canais presentes na área urbana da cidade, que se caracteriza pela presença de esgoto. Com relação a esses canais, $77 \%$ informaram que existem e $58 \%$ lembraram-se do Canal Campos-Macaé (fig. 3). Este canal, que foi construído por mão-de-obra escrava com a finalidade de escoar a produção de canade-açúcar da época, se inicia no Rio Paraíba do Sul, corta o centro da área urbana de Campos e perpassa outros três municípios da região Norte Fluminense, porém sem atravessar o bairro Ururaí. Neste sentido, mais uma vez identifica-se a influência da mídia na construção da memória dos entrevistados, visto que somente $14 \%$ recordaram-se da existência do Canal Campos-Macaé, que ainda assim não faz parte do bairro, em detrimento do Canal Cacumanga que faz.

A maioria dos alunos não se vê como residente das proximidades do rio. Para esses, morar próximo a um rio significa morar na margem ou na mesma rua do recurso. Somente 22,5\% compreendem que apesar de não morarem na margem do rio, residem próximo a este. Esta visão tem a ver com a forma como os alunos percebem os que residem próximo ao rio. Para os estudantes, as áreas que se localizam à margem do rio são perigosas

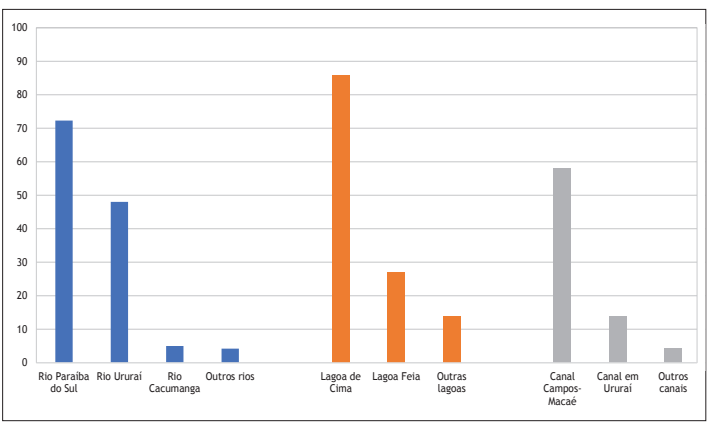

Fig. 3 - A opinião dos alunos sobre os recursos hídricos que existem no município que residem, observa-se que a maioria dos recursos lembrados não são os que se localizam em Ururaí ou proximidades.

Fig. 3 - Students' opinion about the water resources in the municipality where they live; note that most of the resources remembered are not located in or near Ururaí. 
e possuem moradores com baixíssima renda, e ambas as características são mal vistas por eles. Durante o trabalho de campo esta percepção ficou clara a partir de frases preconceituosas pronunciadas em relação ao local e do questionamento (em tom sarcástico) a respeito de haver ou não autorização para o acesso ao mesmo.

Para Souza e Oliveira um conhecimento significativo que passa por uma aprendizagem significativa se constitui uma "importante ferramenta de defesa e de cobrança no convívio em sociedade, principalmente quando o sujeito encontra-se em áreas de risco sócio-ambiental" e não compreende os processos e condicionantes do desastres, atribuindo geralmente à natureza ou a Deus, uma concepção que para as autoras "naturaliza e conforma o fato" (C. J. O. Souza; J. R. Oliveira, 2011, p. 179).

Já com relação ao risco, a quase totalidade dos alunos nunca foi informada que reside em área de risco. Quando questionados sobre o que faz uma residência estar em uma área de risco, $47 \%$ indicaram as enchentes como fator e $26 \%$ os deslizamentos. Interessante ressaltar que uma quantidade substancial destacou a ocorrência de deslizamentos no bairro, apesar do relevo plano que the caracteriza. Neste sentido, identifica-se mais uma vez a influência dos meios de comunicação, na medida em que retratam os deslizamentos que ocorrem nas áreas serranas do estado do Rio de Janeiro.

Em 2008, ano em que ocorreu o mais emblemático e recente evento de inundação, os entrevistados eram crianças com cerca de sete a oito anos, o que explica algumas respostas que foram dadas acerca dos episódios de inundação do bairro. Todavia o objetivo principal desta pergunta era averiguar se as informações sobre os desastres são passadas de uma geração a outra.

Desastre é aqui entendido como: "un acontecimento o serie de sucesos de gran magnitud, que afectan gravemente las estructuras básicas y el funcionamento normal de una sociedad, comunidad o territorio, ocasionando víctimas y daños o pérdidas de bienes materiales, infraestructura, servicios esenciales $o$ medios de sustento a escala o dimensión más allá de la capacidad normal de las comunidades o instituciones afectadas para enfrentarlas sin ayuda, por lo que se requiere de acciones extraordinarias de emergencia. De esta definición se desprende que un desastre no es un fenómeno natural, sino las consecuencias del impacto de un determinado fenómeno de origen natural o vinculado a la tecnología sobre una sociedad, una comunidade y los elementos vulnerables existentes en un território dado" (B. B. Gutiérrez et al., 2004, p.1).

O que foi possível observar é que poucos possuem esse tipo de informação. Por exemplo, a maioria dos alunos não soube informar a frequência das inundações, e um pouco menos que a metade se recordou de sua ocorrência. Dos $46 \%$ que lembraram, a maioria indicou os episódios ocorridos em 2008 e 2012. Além disso, a compreesão que eles possuem do que significa uma casa ser afetada é que esta ocorre quando entra água na residência, quando há necessidade de levantar, tirar os móveis ou ainda sair da residência.

Um pouco menos que a metade informou que recebe aviso quando o rio começa a encher. Entre esses, ficou evidente que o sistema de alerta que os residentes têm acesso, se baseia em uma rede de comunicação informal de moradores e familiares.

Dos 120 entrevistados em 2015, 36 precisaram deixar suas residências e 28 necessitaram de socorro. A ajuda para esses veio de parentes, amigos e vizinhos (nesta ordem). A ajuda relatada consistiu principalmente de recolher os móveis, levantá-los ou fornecer abrigo. Já entre os que precisaram sair de suas residências, a maioria ficou em casa de familiares, $18 \%$ em casa de amigos, e $16 \%$ em abrigos temporários disponibilizados pela prefeitura. Ficou evidente que a rede de informações sobre as cheias do rio muito se assemelha a rede de ajuda dos vitimados, algo que mostra como o vínculo afetivo é decisivo nos desastres locais. Ainda sobre o vínculo afetivo, verificouse que este também ocorre com a localidade em si. Este resultado é proveniente do fato de que quando questionados se mudariam de bairro devido às inundações, $68 \%$ disseram que não. Trata-se de um dado que deixa clara a percepção de identidade, pertencimento e apego dos entrevistados em relação ao bairro, referenciais estes que expressam a valorização da paisagem local como um espaço de significado (R. Costella e N. Shäffer, 2012, p.65).

A maioria dos residentes pertence a famílias de baixa renda ou de classe média baixa. Trata-se de um perfil de morador cuja perda de bens materiais além de penosa é onerosa. Entre os entrevistados afetados, muitos relataram prejuízos significativos, a exemplo de móveis e eletrodomésticos.

Quando questionados a respeito dos fatores que geram as inundações, as respostas variaram entre o lixo, a chuva com grande volume de água, a presença de casas na beira do rio, a ausência da mata ciliar e o assoreamento (nesta ordem). Observou-se que boa parte desconhecia os principais motivos que geram as inundações locais.

Dos alunos que informaram possuir algum tipo de medo das chuvas, somente $8,5 \%$ associaram este medo às inundações (fig. 4). Ainda sobre as chuvas, 69 entrevistados consideraram pior a "chuva constante" em relação a "pancada de chuva", algo que demonstra que há uma associação da inundação local como do tipo gradual. A possível explicação para o baixo percentual relacionado às inundações deve-se ao fato dos maiores eventos terem ocorrido quando os entrevistados eram crianças e também a resiliência que a comunidade possui em se adaptar ao fenômeno.

Os participantes souberam informar com clareza os locais que são inundados com frequência. Apesar de a maioria 


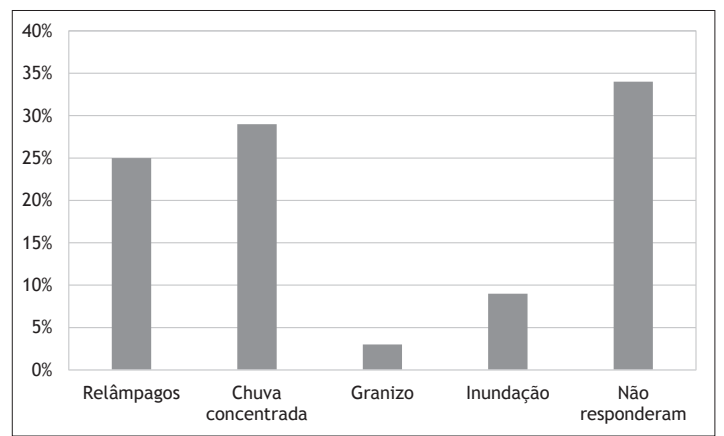

Fig. 4 - Identificação dos motivos que os entrevistados atribuem ao medo de chuva.

Fig. 4 - Identification of the reasons that the interviewees attribute to fear of rain.

considerar importante o aprendizado a respeito da prevenção contra desastres, somente $37 \%$ afirmaram ter tido acesso a informações relacionadas a esse assunto.

Grande parte dos entrevistados demonstrou possuir uma percepção negativa a respeito do futuro do rio, algo que se tornou evidente a partir de afirmações como "o rio irá secar" e "ficará todo poluído". Tais opiniões foram apresentadas pelos participantes desde o início da pesquisa e não foram alteradas até a sua finalização.

Atividades desenvolvidas nas aulas - ano 2016: recurso didático vídeos e jogos

As atividades práticas com os alunos tiveram início com um debate. Para instigar neles questionamentos a respeito do fenômeno inundação foi utilizado um vídeo de um sobrevoo em Ururaí em 2008. O debate, os questionamentos e curiosidades são importantes quando tratamos do ensino. Antunes afirma que nosso aluno é sempre curioso, todavia vivem cercados de estímulos, logo para "disparar" a curiosidade do mesmo é necessário dentre outras ajudar os alunos "a associarem os temas que aprendem à própria vida e aos caminhos por onde caminham" (C. Antunes, 2014, p 28 - 29) e esta primeira atividade de apresentação da proposta para os alunos teve como objetivo "disparar" neles a curiosidade sobre as inundações.

Outras atividades realidadas foram diferentes tipos de jogos, onde a participação ocorreu em grupos. Para Antunes é importante mesclar diferentes manei-ras de se ministrar as aulas, em destaque o autor coloca os jogos operatórios (C. Antunes, 2014, p.105). Esses tipos de jogos são procedimentos metodológicos que utilizam regras semelhantes a um jogo de competição. Os jogos mencionados a seguir foram realizados nessa abordagem.

O primeiro jogo, chamado de "Batalha naval", teve a intensão de relembrar conteúdos trabalhados anteriormente com os alunos e prepará-los para o jogo "Descubra a inundação. O segundo jogo chamado de "Encontre os erros" os alunos tiveram acesso a um mapa de Ururaí com erros propositais referentes à escala, legenda, posicionamento de ruas, praça, usina, rio, canal, entre outros (fig. 5). A respeito do emprego dos diferentes mapas temáticos locais, seus usos foram propositais, a fim de valer-se de experiências anteriormente adquiridas pelos alunos, tal como proposto por Oliveira (L. Oliveira, 2010, p.25). Nesta, quase a totalidade dos alunos conseguiram identificar os erros referente a espacialização dos objetos, os diferentes pontos e elementos que compõem o núcleo urbano Ururaí. Já o jogo "Descubra a inundação", onde a partir do uso de imagens do Google Maps impresso e com dicas de coordenadas geográficas, os grupos colaram adesivos em locais em que ocorriam as inundações no bairro, os grupos demonstraram ter um conhecimento prévio sobre os locais que são mais vulneráveis (fot. 4).

O último jogo proposto para os alunos, chamado de "Tabuleiro Humano", foi realizado já no final do ano letivo, após a aula de campo, a pesquisa que os alunos realizaram e as demais atividades. Chamado de "Tabuleiro Humano" Foi significativo observar a mudança nos resultados obtidos. Por exemplo, foi possível averiguar que os

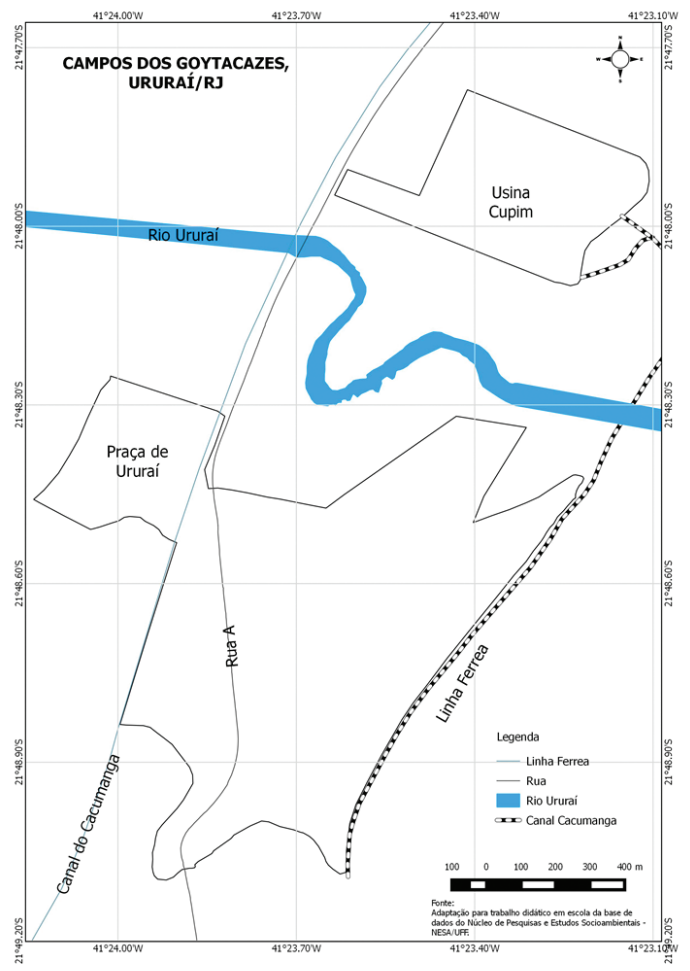

Fig. 5 - Na imagem acima as legendas foram trocadas, o nome da principal via de acesso, os recursos hídricos e outros elementos.

Fig. 5 - The name of the main access road, water resources and other elements have been changed in the key of the above diagram. 


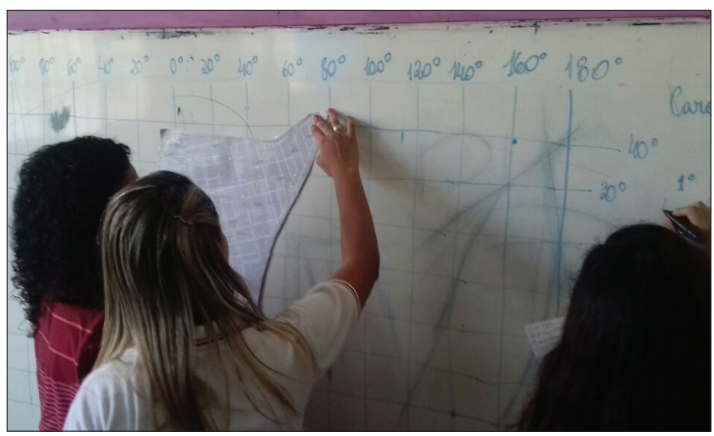

Fot. 4 - Neste jogo chamado "Descubra a inundação" observa-se a interação entre as alunas ao escolher os pontos de inundação do bairro por intermédio da imagem impressa do Google Maps (Fonte: C. Almeida, Julho de 2016).

Photo 4 - In this game called "Discover the flood" we see the interaction between the students when choosing the flood points of the neighborhood on the printed image of Google Maps. (Source: C. Almeida, July 2016).

alunos conseguiram identificar, diferenciar as áreas de risco de inundações e de alagamentos e os motivos que geram esses fenômenos. Essa diferença entre esses tipos de riscos para Lourenço leva que habitualmente sejam confundidos. Isso porque quase sempre coincide com o risco de inundação, porém a gênese desse fenômeno é diferente, do ponto de vista hidrológico o risco de alagamento ocorre quando há "uma acumulação de água em áreas aplanadas da superfície terrestre, mas resultando direta e exclusivamente da precipitação, em virtude de dificuldades de escoamento superficial $e$ de infiltração, por saturação dos solos e das rochas" (L. Lourenço, 2015, p.32). Eles também aprenderam como observar o risco de inundação, isto é, eles compreenderam que quando ocorre muita chuva na "cabeceira" (sic) do rio os moradores já devem ficar em estado de alerta devido a cheia do mesmo, ou ainda que obras na tubulação das águas pluvias, a fim de diminuir os alagamentos são necessárias, dentre outras medidas. Desta forma, os alunos conseguiram desenvolver um pensamento crítico sobre as diferentes causas de inundações em seu lugar, não apenas identificando-o como no início do projeto.

Atividades desenvolvidas nas aulas - ano 2016: recurso didático aula de campo

Nesta atividade foi possível fazer a problematização da paisagem por meio da observação, uma medida que auxilia na construção do conhecimento referente à espacialidade materializada conforme proposto por Cavalcanti (L. Cavalcanti, 2010 a, pp.146 - 147). Os eixos temáticos abordados com os alunos durante o desenvolvimento desta atividade foram: relevo, vegetação, bacia hidrográfica, clima, usos do rio, processos de urbanização e questão social. Dentro desses eixos temáticos outros subtemas foram analisados, sempre voltados para as inundações do bairro (fot. 5). Por exemplo em relevo foi debatido como é a estrutura de um rio em uma planície e o comportamento do mesmo quando há cheia e inundação; ao tratar do clima ocorreu uma conversa sobre como o clima no município de campos influencia nas inundações; ou ainda como é formada a bacia hidrográfica do rio, como é a montante e jusante; ou ainda os processo de transformação no referido núcleo urbano e de que forma essas transformações acarretaram no maior risco de desastre etc.

Os três mapas temáticos utilizados com os alunos durante o campo tiveram como função de auxiliar na percepção e mapeamento de riscos, e na melhor interpretação dos eixos temáticos acima citados e sua relação com as inundações locais. Proposta esta também utilizada por Bragança, Felizardo e Afonso : A vivência é significativa tanto para criar habilidade de mapear e ler mapas como para a construção do domínio do espaço, para a construção do conhecimento (C. B. Bragança, A. M. Felizardo, A. E. Afonso, 2017, p. 3314).

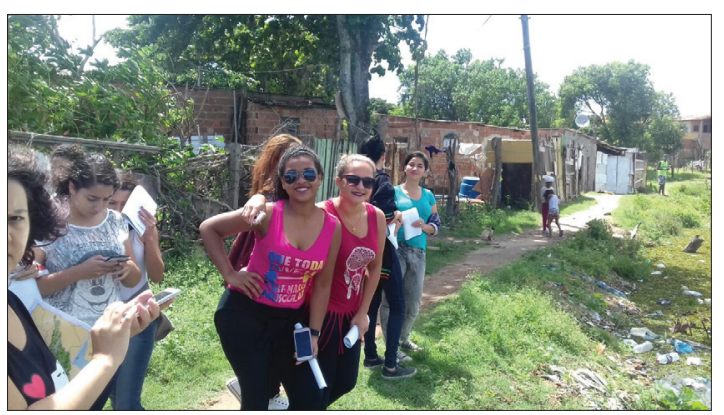

Fot. 5 - A fotografia foi tirada na margem do rio Ururaí, em um dos pontos de maior vulnerabilidade. Na imagem pode-se observara estrutura das casas e o lixo em suas margens. Após a explicação os alunos ficaram à vontade para tirar suas fotografias e realizar suas anotações (Fonte: C. Almeida, Outubro de 2016).

Photo 5 - The photograph was taken on the bank of the river Ururaí, at one of the most vulnerable points. We can see the structure of the houses and the garbage on its banks. After an explanation, the students were happy to take their photos and make their notes. (Source: C. Almeida, October 2016).

Atividades desenvolvidas nas aulas - ano 2016: recurso didático pesquisa e apresentação

A atividade que coube aos alunos pesquisar e apresentar obteve apenas $56 \%$ de adesão e o nível de comprometimento variou muito entre os que se envolveram. Os que participaram obtiveram as informações necessárias por intermédio das observações no bairro, da pesquisa de campo, das memórias pessoais, de antigos moradores e parentes, além de jornais impressos e telejornais locais. Somente 
um grupo com quatro alunos não conseguiram atingir a proposta, pois ficaram "presos" em conceitos sobre os diferentes tipos de relevo, obtendo dificuldade em associar o relevo local, sua formação, transformações e a relação do mesmo com as inundações. Os demais grupos, mesmo de modo não tão sistemático como na academia, coletaram as informações de diferentes formas e durante as apresentações ficou evidente que buscaram desenvolver alguns aspectos conceituais e depois se propuseram a transportá-los para a realidade de seu bairro. A ideia de pesquisa como um princípio educativo , de acordo com Demo é capaz de emancipar o sujeito: "Pesquisa é um processo que deve aparecer em todo trajeto educativo, como princípio eudcativo que é, na base de qualquer proposta emancipatória" ( $\mathrm{P}$. Demo, 2011, p. 17). Ainda para o autor "a pesquisa é um ato processual de investigação diante do desconhecido e dos limites que a natureza e a sociedade nos impõem" (P. Demo, 2011, p. 16). Desta forma, esse tipo de atividade propicia um conhecimento local de base mais empírica e fornece ferramentas que os alunos poderam utilizar para pesquisarem outros processos tendo sobre eles o mesmo pensamento crítico.

\section{Questionário e entrevistas pós atividades - ano 2016}

O segundo questionário aplicado já no final de todas as atividades teve como objetivo averiguar a opinião dos envolvidos sobre as atividades propostas ao longo do ano letivo. Quanto aos resultados, entre as atividades realizadas (fot. 6 e 7), os alunos deram destaque à aula de campo e aos jogos "Batalha naval" e "Encontre os erros". Estes afirmaram ainda que os jogos, inclusive o último jogo desenvolvido chamado de "Tabuleiro Humano" (fot. 7), são uma boa forma de aprender e de se divertir, isso porque estes tipos de atividades geram polêmicas, debates e trocas de idéias que em atividades comuns não seriam possíveis.

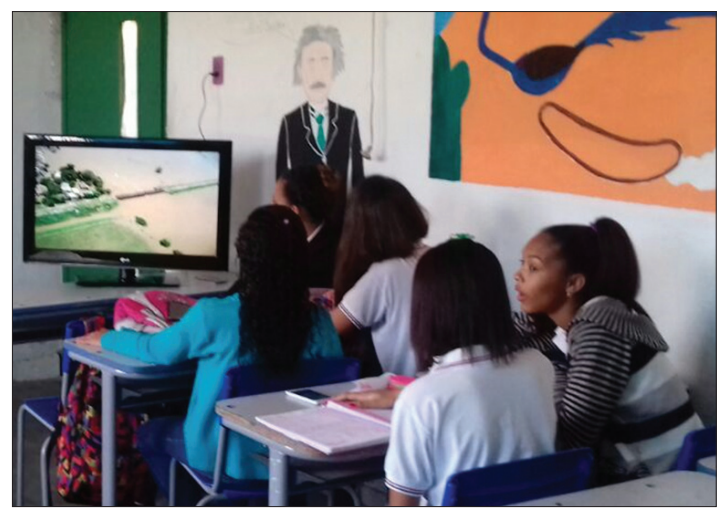

Fot. 6 - Apresentação do vídeo aéreo referente ao evento de 2008 (Fonte: C. Almeida, Julho de 2016).

Photo 6 - Presentation of the aerial video related to the event of 2008 (Source: C. Almeida, July 2016).
Ainda sobre a aula de campo , 71\% responderam que ele foi "legal", porque aprenderam mais sobre a matéria dada e sobre o bairro. Contudo, cerca de $58 \%$ não possuem o costume de frequentar ou nunca estiveram nos lugares, mesmo que boa parte resida em Ururaí há mais de dez anos.

Sobre a pesquisa que realizaram a maioria prefere de fato estudar temas ligados ao seu lugar, quase $70 \%$. Aproximadamente $20 \%$ dos entrevistados disseram que preferem outros lugares, pois é mais interessante ou porque alegaram ser difícil encontrar informações locais.

\section{Considerações finais}

Ao fim das atividades, grande parte dos alunos pode compreender melhor as causas das inundações em sua localidade, informando inclusive que as transformações do bairro, como asfaltamento das ruas, adensamento populacional e a falta de tubulações destinadas ao escoamento de águas pluviais são fatores que contribuem para o agravamento das inundações.

O uso do tema inundação como fonte de análise e o seu desenvolvimento com os alunos em uma perspectiva de educação em Geografia permitiu que diversos conteúdos, competências e habilidades relacionadas ao currículo do $1^{\circ}$ ano do Ensino Médio fossem alcançados, além de proporcionar um conhecimento mais específico acerca de uma categoria de desastre que os afeta. Nesse sentido, o procedimento utilizado mostrou-se proveitoso na medida em que viabilizou o reconhecimento e a percepção crítica a respeito dos processos socioambientais atuantes em sua realidade, a partir da desconstrução e reconstrução de alguns conceitos trabalhados ao longo da pesquisa.

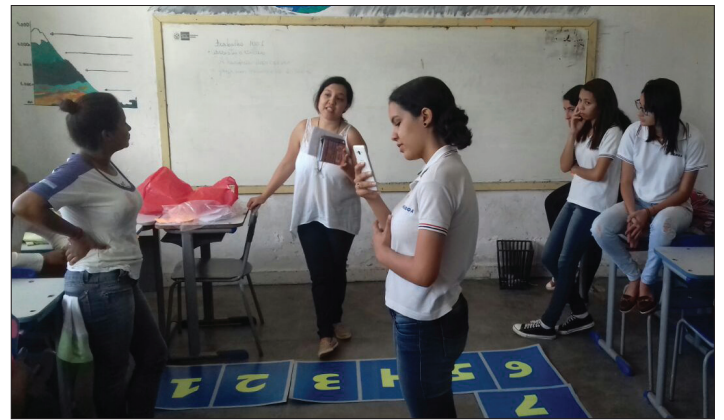

Fot. 7 - Realização do jogo intitulado "Tabuleiro Humano" de perguntas e respostas, no qual os alunos que acertassem poderiam jogar o dado e caminhar nas casas. Na imagem a aluna espera a professora terminar a pergunta

(Fonte: C. Almeida, Novembro de 2016).

Photo 7 - Playing the questions and answers game called "Human Board", in which the students who wanted to play could throw the dice and enter the squares. In the picture the student is waiting for the teacher to finish the question (Source: C. Almeida, November 2016). 
Contudo, verifica-se que o uso de diferentes práticas de ensino não será suficiente para promover uma aprendizagem geográfica significativa se estas não estiverem ancoradas em uma base teórica e de pesquisa sólida. Negligenciá-la durante o processo de ensino/ aprendizagem é algo que pode culminar na assimilação de um conhecimento vago, rotulado e sem sentido para os alunos, os quais são fatores que promovem o seu desestímulo. Neste sentido, destaca-se a necessidade de os professores fazerem uso de todas as ferramentas que estiverem ao seu ao alcance, a fim de instrumentalizarem o olhar e o pensamento crítico dos estudantes, inclusive buscando a problematização de seu meio.

A pesquisa também forneceu dados que oportunizaram um maior e melhor desenvolvimento das práticas do ensino de Geografia, na medida em que as diferentes atividades levaram em consideração as percepções dos diferentes sujeitos que estiveram envolvidos no processo de ensino e aprendizagem.

Como expõe Castrogiovanni, "o ensino somente por conteúdos, parece não satisfazer mais. Precisamos trabalhar com questões que evoquem a prática, a realidade contextualizada do aluno, com suas necessidades, seus interesses, suas tensões" (A. C. Castrogiovanni, 2007, p.22). Daí a necessidade de se desenvolver diferentes abordagens metodológicass que fizessem uso das inundações, pois concomitantemente permitiu lecionar de forma prática e contextualizada a realidade, os conteúdos e habilidades referentes ao currículo, além de permitir a construção do conhecimento de forma a auxiliar na prevenção e mitigação dos desastres relativos a água. Pois contribui com a sua percepção crítica, tanto a respeito do ambiente vivido, quanto no que se refere aos desastres relacionados à água.

\section{Referências bibliográficas}

Afonso, A. E. (2015 a). A Geografia da natureza no ensino de Geografia: propostas para a educação ambiental e preventiva de riscos naturais. Revista Giramundo, Rio de Janeiro, v.2 n 4, p.83-93.

Afonso, A. E. (2015 b). Perspectivas e possibilidades do ensino e da aprendizagem em Geofrafia física na formação de professores. Tese apresentada ao Programa de Pós-Graduação em Geografia da Universidade Federal Rio de Janeiro - UFRJ, Rio de Janeiro, p.236.

Acosta, V. G. (2015). La construcción social de la prevención. Um concepto em construcción. In: Siqueira, Antenora; et al.(Orgs). Riscos de desastres relacionados à água: aplicabilidade de bases conceituais das Ciências Humanas e Sociais para a análise de casos concretos. RiMambra, São Paulo, pp. 45 - 55.
A., C. (2014). Geografia e Didática. Vozes, Petrópolis, p. 150.

Araújo, M. M. A. (2012). Riscos naturais numa perspectiva de educação em Geografia, no $3^{\circ}$ ciclo do Ensino Básico - um estudo de caso no Vale do Cavalum (Penafiel) (Dissertação de Mestrado) Apresentada à Faculdade de Letras, Universidade do Porto, p. 169.

Ayala, I. A. (2002). Geomorphology, natural hazards, vulnerability and preventio of natural disasters in developing countries. Geomorphology, v.47, pp.107 - 142

Ausubel, D.P. (2002). Adquisición y retención del conocimiento: Uma perspectiva cognitiva. Paidós, Barcelona, p.281.

Barros, M. T. L. de (2005). Drenagem urbana: bases conceituais e planejamento. In: PHILIPPI Jr. A. (org). Saneamento, saúde e ambiente - fundamentos para um desenvolvimento sustentável. 1ed. Editora Manole, São Paulo, Cap.7. p. 228.

Bragança, C. B., Felizardo, A. M., Afonso, A. E. (2017). Ensino de Geografia por meio da temática de riscos naturais no Ensino Básico. psbgfa, v. 1, Campinas, p. $3309-3316$.

Cabaní, M. L. P. (2004). A aprendizagem escolar do ponto de vista do aluno: os enfoques de aprendizagem. In: Coll, César; et al.(Orgs). Desenvolvimento psicológico e educação, Artmed, Porto Alegre, pp. 193-208.

Campos, A. (1999). Educación y prevención de desatres. UNICEF, San José, p.145.

Castrogiovanni, A. C.(org.) (2007). Ensino de geografia: caminhos e encantos. EDIPUCRS, Porto Alegre, p. 111.

Cavalcanti, L. de S. (2010 a). Geografia, escola e construção de conhecimentos. Papirus, Campinas, p. 192.

Cavalcanti, L. de S. (2010 b). A geografia escolar e a cidade: Ensaios sobre o ensino de geografia para a vida, Papirus, Campinas, p. 190.

Cartagena, S. M. C.(2012). Redução de riscos de desastres nas escolas. CEPED UFSC, Florianópolis, p.10.

Costella, Roselane Zordan; Shäffer, Neiva Otero (2012). A Geografia em projetos curriculares: ler o lugar $e$ compreender o mundo, Edelbra, Brasília, p. 128.

Coutinho, C. P., Sousa, A., Dias, A., Bessa, F., Ferreira, M. J. R. C., \& Vieira, S. R. (2009). Investigação-Acção: metodologia preferencial nas práticas educativas. Psicologia, Educação e Cultura, v.XIII, n² 2, pp.355 - 380.

Demo, P. (2011). Pesquisa: princípio científico $e$ educativo, 14ed. Cortez, São Paulo , 128p.

Fantin, M. E., Tauscheck, N. M. (2007). Metodologia do ensino de geografia, Ibpex, Curitiba, p. 128. 
Goulart, L. B.(2014). Aprendizagem e ensino: uma aproximação necessária à aula de Geografia. In: Castrogiovanni et al. (Orgs). O Ensino de Geografia e suas composições curriculares. Mediação, Porto Alegre, pp. $21-30$.

Gregory, K. J., Walling, D. E. (1973). Introduction. In: Drainage basin form and process. 1 ed. Edward Arnold (Publishers) Ltd., Londres, Cap1.

Gutiérrez, B. B. et al. (2004). Medicina de Desastres, La Habana, p.206

Knight, D. W. (2006). Introduction to flooding and river basin modelling. In: Knight, Donald W.; Shamseldin, A. Y. (Orgs.) River basin modelling for flood risk mitigation. 1 ed. Taylor \& Francis Group plc/ Balkema, Leiden, Cap.1.

Leite, A. F. (2013). Comportamento espaço-temporal das chuvas do Norte Fluminense (RJ). In: Leite, Adriana Filgueira; Gomes, Marcos Antônio Silvestre (orgs) . Dinâmica ambiental e produção do espaço urbano $e$ regional no Norte Fluminense. Essentia, Campos dos Goytacazes (RJ), p. 11 - 34.

Leopold, L. B.(1994). Flow variability and floods. In: $A$ view of the river. 1ed. Havard University Press, Cambridge, Cap.7.

Libâneo, J. C. (2013). Didática, 2ed, Cortez, São Paulo, p.281.

Lourenço, L.(2015). Risco, perigo e crise: pragmatismo e contextualização In: Siqueira, Antenora; et al.(Orgs). Riscos de desastres relacionados à água: aplicabilidade de bases conceituais das Ciências Humanas $e$ Sociais para a análise de casos concretos. RiMambra, São Paulo, pp. 3 - 43. Disponível em: http://www. uc.pt/fluc/nicif/Publicacoes/Estudos_de_Colaboradores/PDF/Livros_e_Guias/2015_RiscosDesastres_ LL_.pdf

Luckesi, C. C. (2008). Avaliação da aprendizagem escolar: estudos e proposições, 19ed. Cortez, São Paulo, p.181

Malagodi, M. A. S., Siqueira, A. M. da M. (2012). Inundação e ação social em Campos dos Goytacazes (Rio de Janeiro, Brasil). VII Congresso Português de Sociologia, Porto, p.2-17.

Marandola Jr., E., Hogan, D. J. (2004). Natural hazards: o estudo geográfico dos riscos e perigos. Ambiente \& Sociedade, v.7, n.2, jul/dez, pp. 95-109.

NESA - NÚCLEO DE ESTUdOS SóCIO AMBIENTAIS; Siqueira, A. M. da M. (coord.) (2016). Cartografia socioambientais e mapeamento de áreas de risco de inundações no Norte Fluminense: subsídios a elaboração de sistemas de alerta. Relatório Final Projeto FAPERJ, Universidade Federal Fluminense, p. 18
Oliveira, L. de (2010). Estudo metodológico e cognitivo do mapa. In: Almeida, Rosângela Doin de (Org.). Cartografia Escolar, Contexto, São Paulo, pp. 15-41.

Ramos, C. (2005). Programa de Hidrogeografia. Centro de Estudos Geográficos, Univ. de Lisboa, p. 123.

Rocha, J. S. (1995). Prevenção de inundações e reabilitação de edifícios em zonas inundáveis. Territorium 2.1995, p. 11-20. Disponível em: http://www.uc.pt/fluc/nicif/riscos/Documentacao/ Territorium/T02_artg/T02_artg02.pdf

SEEDUC - SECRETARIA DE EDUCAÇÃO DO ESTADO DO RIO DE JANEIRO (2012). Currículo Mínimo 2012 - Geografia. Rio de Janeiro, p.14

Severino, A. J., Severino, E. S. (2012). Ensinar e Aprender com Pesquisa no Ensino Médio, Cortez, São Paulo, p. 142.

Siqueira, A. M. da M., Malagodi, Sampaio, M. A. (2013). Desastres e remoções em campos dos Goytacazes/ RJ: o caso Ururaí. In: Leite, Adriana Filgueira; Gomes, Marcos Antônio Silvestre (orgs) . Dinâmica ambiental e produção do espaço urbano e regional no Norte Fluminense. Essentia, Campos dos Goytacazes (RJ), p. 35 - 66.

Souza, C. J. de O. (2013). Riscos, geografia e educação. In: Lourenço, Luciano Fernandes; Mateus, Manuel Alberto. (Orgs). Riscos naturais, antrópicos e mistos: Homenagem ao Professor Doutor Fernando Rebelo, Universidade de Coimbra, Coimbra, pp. 127-142. Disponível em: https://www.uc.pt/fluc/depgeotur/publicacoes/Livros/livro_homenagem_FRebelo/127_142

Souza, C. Ju. de O., Oliveira, J. R. (2011). Representação de áreas de riscos sócio-ambientais: Geomorfologia e Ensino. Territorium 18, pp. 175 - 184. Disponível em: https://www.uc.pt/fluc/nicif/riscos/Documentacao/Territorium/T18_artg/Carla_Souza.pdf

Stefanello, A. C.(2009). Didática e Avaliação da Aprendizagem no Ensino de Geografia, Saraiva, São Paulo, p. 159.

Thywissen, K. (2006). Components of Risk. A comparative Glossary. Unithed Nations University, Germany, p.50.

Tomita, L. M. Saito (1999). Trabalho de campo como instrumento de ensino em Geografia. Geografia, Londrina, v.8, n.1, jan/jun, pp. 13 - 15.

UNESCO; UNICEF; Kagawa, F., Selby, D. (2012). Redução do risco de desastres nos currículos escolares: estudo de casos de trinta países. UNICEF and UNESCO, France, p.218.

Zabala, A. (1998). A prática educativa: como ensinar. Trad. Ernani F da F Rosa. ArtMed. Porto Alegre, p. 224. 